\title{
Role of (E)- $\beta$-farnesene in systematic aphid prey location by Episyrphus balteatus larvae (Diptera: Syrphidae)
}

\author{
FrÉDÉric FRANCIS ${ }^{1}$, ThiBAUt MARTIN², GEORges LOGNAY² and ERIC HAUBRUGE ${ }^{1}$ \\ ${ }^{1}$ Unit of Functional and Evolutionary Entomology, ${ }^{2}$ Unit of Analytical Chemistry, Gembloux Agricultural University, \\ Passage des Déportés 2, B-5030 Gembloux, Belgium; e-mail: francis.f@fsagx.ac.be
}

Key words. Syrphidae, infochemical, (E)- $\beta$-farnesene, Episyrphus balteatus, larvae, prey localisation, olfactometer

\begin{abstract}
The foraging behaviour of beneficials such as aphidophagous predators depend largely on volatile compounds emitted by potential preys. Even if polyphagous predatory species are considered, all the potential preys are not systematically localised and accepted. In this work, chemical cues from different aphids and plants, each alone or in association, were studied to elucidate their role in prey location. Using a four-arm olfactometer, attraction of combinations of three aphid (Megoura viciae, Acyrthosiphon pisum and Aphis fabae) and one plant (Vicia faba) species for Episyrphus balteatus larvae was observed. Predatory hoverfly larvae were attracted by all tested stimuli in the presence of aphids, whatever the species. Whole or crushed aphids and also aphids on bean plant parts were attractive to syrphid larvae, but the host plant alone did not present any infochemical role for $E$. balteatus. Identification and quantification of the volatile releases from aphid and plant species, alone or in association, were performed using SPME and GC-MS methods. Aphid alarm pheromone, (E)- $\beta$-farnesene, was found in the volatile pattern of each aphid and was tested for its role as an effective kairomone for the hoverfly.
\end{abstract}

\section{INTRODUCTION}

With their importance in pest control, predators and parasitoids are fascinating subjects for ecological studies. Beneficial insects are sensitive to chemical aspects of the multitrophic environment, particularly with regard to host location (Poppy, 1997). To localise their preys in natural habitats, entomophagous beneficials use numerous chemical cues emitted by preys and host plants, each alone or in association (Vet \& Dicke, 1992). Plenty of different chemical cues correspond to the diversity of associations between potential prey and host plant species. Recently, responses of Coleomegilla maculata L. (Coccinellidae), Coccinella septempuncata L. (Coccinellidae) and Chrysoperla carnea (Chrysopidae) were found to be related to semiochemicals released from potential prey species and their host plants (Zhu et al., 1999; Al Abassi et al. 2000); they use chemical cues to locate their preys. One molecule, (E)- $\beta$-farnesene, was identified to be effective kairomone for the predators. The importance of this molecule as kairomone was confirmed by Francis et al. (2004a) for the two-spot ladybird. Indeed, only aphids releasing (E)- $\beta$-farnesene alone were found to be attractive for Adalia bipuncata L.

Although $A$. bipunctata and $C$. septempunctata are abundant in many agro-ecosystems, several hoverfly species are the main effective predators during their larval stages in crops (Tenhumberg \& Poehling, 1995). Among them, Episyrphus balteatus DeGeer is the most commonly recorded syrphid species on agricultural lands (Chambers et al., 1986) and was already studied to investigate predator prey location (Bargen et al., 1998). In order to study the relation between volatile emission from aphids and prey location by E. balteatus larvae, three aphid species were selected according to the volatile pat- tern they released. While Acyrthosiphon pisum Harris and Aphis fabae Scopoli only emit (E)- $\beta$-farnesene, Megoura viciae Buckton presents a mixture of three terpene hydrocarbons [ $\alpha$-pinene $(11.8 \%), \quad \beta$-pinene $(82.0 \%)$ and limonene $(6.2 \%)$ with no (E)- $\beta$-farnesene, an effective kairomone for several coccinellid aphid predators (Francis et al., 2004a,b). Using a 4-way olfactometer, the syrphid predator response towards several aphid and host plant combinations was assessed. The different odour sources corresponded to potential situations met by $E$. balteatus in its natural habitats. The relation between prey suitability, volatile release and behavioural response of the predator were discussed in relation to the potential use of hoverflies in biological control of aphids.

\section{MATERIALS AND METHODS}

\section{Plant and insect rearing}

Broad beans (Vicia faba L.) were grown in $10 \mathrm{~cm}$ diameter plastic pots containing a $1: 1$ mixture of perlite : vermiculite in controlled environmental rooms at $20 \pm 2{ }^{\circ} \mathrm{C}$ temperature and 16 $\mathrm{h}$ daylight photoperiod.

Acyrthosiphon pisum (Harris), Megoura viciae Buckton and Aphis fabae Scopoli were taken from long-term cultures reared on bean plants in the laboratory for many years. Plants were inoculated at the 2-3 true leaf stage with one of the aphid species. Each combination of aphid and plant species was isolated in separate conditioned rooms at $20^{\circ} \mathrm{C} \pm 2{ }^{\circ} \mathrm{C}$ and $16 \mathrm{~L}: 8 \mathrm{D}$ photoperiod. Mass rearing of Episyrphus balteatus Degeer had also been maintained for many years in the laboratory. Control syrphid larvae were reared in aerated plastic boxes and fed with $M$. viciae on $V$. faba. From hatching, larvae which were used in olfactometry assays were individually reared in $5 \mathrm{~cm}$ diameter Petri dishes. When they were $24 \mathrm{~h}$ old, hoverfly larvae were used to test the chemical cues. 


\section{Olfactometer setup}

The 4-way olfactometer which was used to test the behavioural responses of hoverfly larvae towards several stimuli was similar to that described by Vet et al. (1983). Compressed air was circulated through active charcoal and a water bottle before entering the exposure chamber. Air left the latter through a hole in the chamber roof. Airflow in each of the four arms was adjusted with a flowmeter to $60 \mathrm{ml} \cdot \mathrm{min}^{-1}$, thereby creating four equal distinct fields in the exposure chamber. Odour-emitting samples were placed in a $25 \mathrm{ml}$ glass flask linked by plastic tube to one of the four olfactometer arms. The olfactometer system was placed in a controlled temperature room at $20 \pm 2^{\circ} \mathrm{C}$. Before the beginning of the olfactometer assays, the system was cleaned with pure ethanol and rinsed with distilled water.

\section{Odour sources as chemical cues}

Several stimuli were tested as odour sources:

(1) undamaged, unstressed whole aphids (A. pisum, M. viciae or A. fabae);

(2) crushed aphids representing a stressed aphid colony (one of the three previous species;

(3) a host-plant section (a part of a bean stem with some leaves);

(4) a host-plant section with aphids: i.e. a part of a bean stem with aphids, assumed to represent volatile production corresponding to aphids feeding on the plant;

(5) pure (E)- $\beta$-farnesene $(2 \mu \mathrm{g})$ in hexane solution on Whatman paper.

Aphid and host-plant samples (250 mg of insects or plant) were placed in the glass flask, in the air stream of one of the four arms of the olfactometer. The three aphid species were selected for their volatile releases: $A$. pisum and $A$. fabae only released (E)- $\beta$-farnesene whilst a mixture of $\alpha$ - and $\beta$-pinene and limonene were emitted from M. viciae (Francis et al., 2004b).

\section{Behavioural observations}

Hoverfly larvae ( $24 \mathrm{~h}$ old, $\mathrm{n}=20$ per stimulus) were individually observed in the olfactometer. Each individual was placed at the centre of the exposure chamber and observed during $20 \mathrm{~min}$. The olfactometer area was divided in one central area and four other ones related to the four odour sources. After insect introduction into the olfactometer, stay durations in each area were determined. Localisation in one of the four areas at the end of the observation duration was considered to be the final behavioural choice of the hoverfly larva. Every 5 observations, the position of the odour fields was changed. The exposure chamber was cleaned with pure ethanol and rinsed with distilled water after each assay.

\section{Analysis of volatile releases from aphids and plants}

Aphid and plant samples $(250 \mathrm{mg})$ were crushed with a glass pestle in a glass tube adapted to the SPME method. Each aphid species was tested at least in duplicate. Crushed samples were first maintained for $30 \mathrm{~min}$ at $30.0 \pm 0.2^{\circ} \mathrm{C}$ in glass tubes adapted to SPME. The volatile metabolites were sampled for 30 min with $100 \mu \mathrm{m}$ PDMS (polydimethylsiloxane) SPME fibers from Supelco ${ }^{\circledR}$ and immediately analyzed by GC-MS on an Hewlett Packard HP5972 Mass spectrometer coupled with an HP5890 series II gas chromatograph. The following analytical conditions were used: split-splitless injection at $250^{\circ} \mathrm{C}$, HP5-MS ( $5 \%$ phenyl-dimethylpolysiloxane) column $(30 \mathrm{~m} \times 0.25 \mathrm{~mm}, \mathrm{df}$ $=1 \mu \mathrm{m})$. Samples were purged with $\mathrm{He}$ at $4 \mathrm{ml} \mathrm{min}{ }^{-1}$ for 11 min, and the temperature program was from $40^{\circ} \mathrm{C}(1 \mathrm{~min}$ hold $)$ to $180^{\circ} \mathrm{C}$ at $6^{\circ} \mathrm{C} \cdot \mathrm{min}^{-1}$ then to $280^{\circ} \mathrm{C}$ at $15^{\circ} \mathrm{C} \cdot \mathrm{min}^{-1}$. MS spectra were obtained in the EI mode at $70 \mathrm{eV}$ (scanned mass range from
30 to $300 \mathrm{amu}$ ). The analytes were identified on the basis of their retention times and by interpretation of MS fragmentation patterns. Spectra were compared to those of the Wiley238.L spectral library. (E)- $\beta$-farnesene in hexane was analyzed by the same procedure.

\section{Statistical analysis}

Observed frequencies related to the final choice of $E$. balteatus to localise the prey were compared to the corresponding expected frequency ( 1 odour source and 3 controls) using a $\chi^{2}$ test. Relative stay durations of hoverflies were compared by the contrast method using the residual mean square from ANOVA after $\arcsin \sqrt{x}$ transformation (Dagnelie, 1973).

\section{RESULTS}

Observation of times spent by the hoverflies in each of the four olfactometer arms confirm the attractive effect of the whole unstressed (Fig. 1) and crushed (Fig. 2) aphids

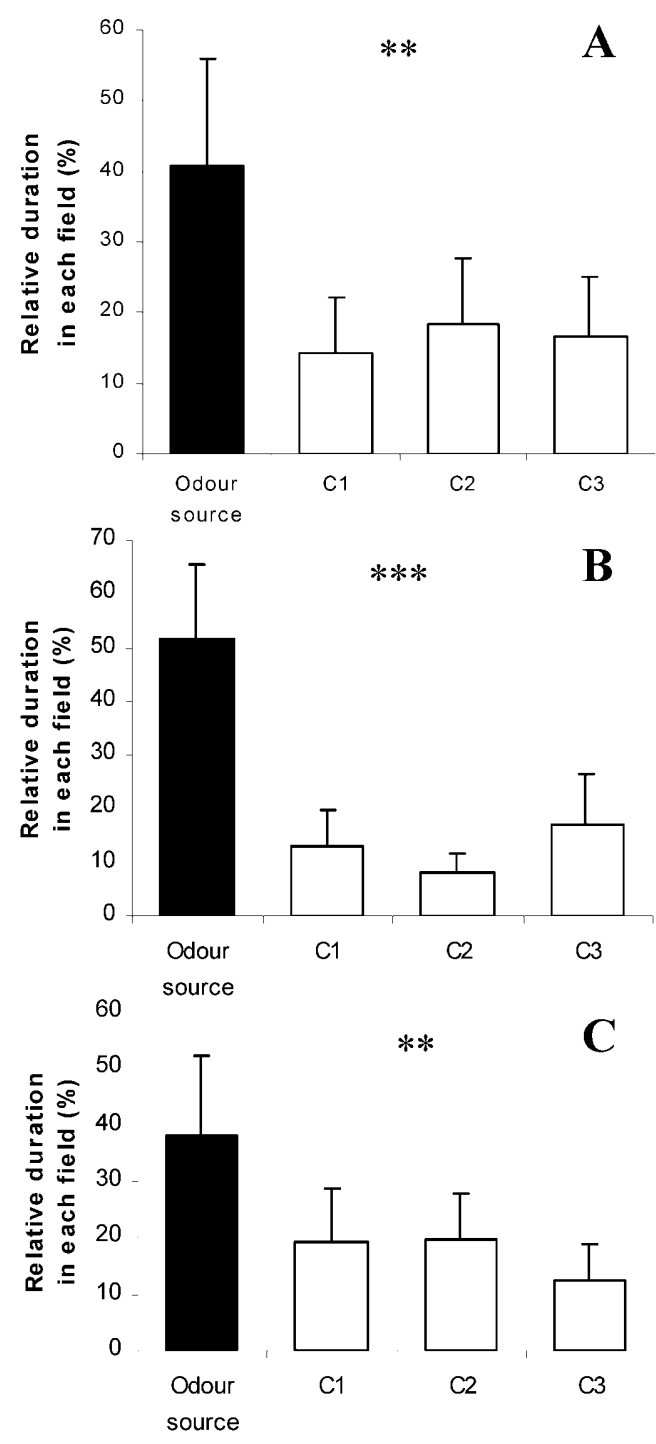

Fig. 1. Mean relative time (\%) spent in each field of a four-arm olfactometer by Episyrphus balteatus larvae exposed to unstressed whole Megoura viciae (A), Acyrthosiphon pisum (B) and Aphis fabae (C) reared on Vicia faba. Error bars represent standard deviation of the mean. $* *$ and $* * *$ indicate significant differences at $\mathrm{P}<0.01$ and $\mathrm{P}<0.001$ respectively. 

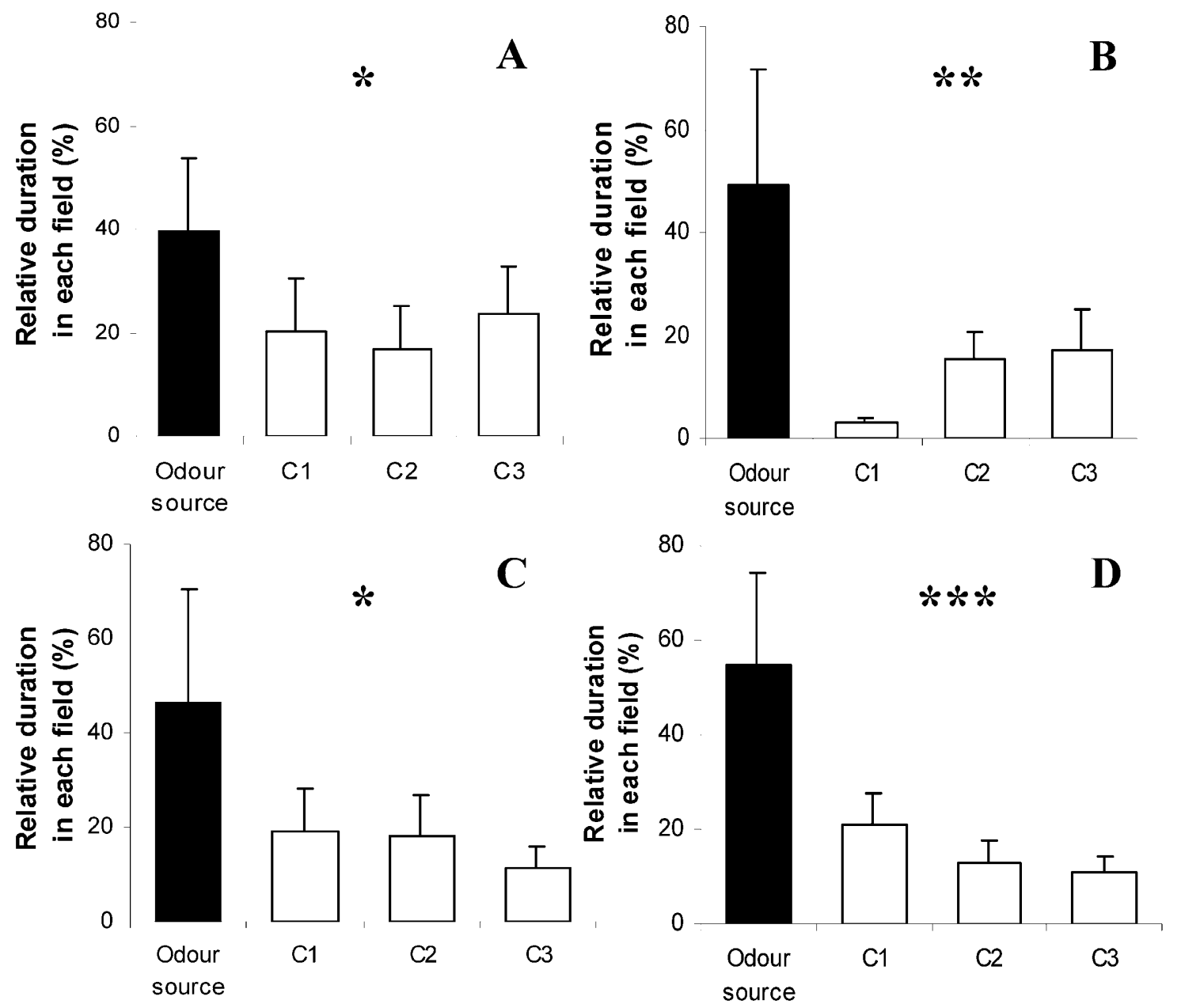

Fig. 2. Mean relative time (\%) spent in each field of a four-arm olfactometer by Episyrphus balteatus larvae exposed to crushed Megoura viciae (A), Acyrthosiphon pisum (B) and Aphis fabae (C) reared on Vicia faba. Pure (E)- $\beta$-farnesene (2 $\mu \mathrm{g}$ on Whatman paper) was also used as odour source (D). Error bars represent standard deviation of the mean. *, **,*** indicate significant differences at $\mathrm{P}<0.05, \mathrm{P}<0.01$ and $\mathrm{P}<0.001$ respectively.

reared on $V$. faba for E. balteatus larvae. Similar results were observed when testing separately the three aphid species in association with the host plant on the hoverfly larvae behaviour (Fig. 3). Plant leaves alone used as a chemical cues elicited no significant attractive effect on times spent by the syrphid larvae in the olfactometer field relative to the odour source sample. Finally, the (E)- $\beta$ -

TABLE 1. Responses of Episyrphus balteatus larvae towards crushed, unstressed whole aphids and plant-aphid associations as odour sources $(\mathrm{n}=20)$. Pure $(\mathrm{E})-\beta$-farnesene $(2 \mu \mathrm{g}$ on Whatman paper $)$ and plant alone $(V \cdot f a b a)$ were also used as chemical cues.

\begin{tabular}{|c|c|c|c|c|c|}
\hline Aphid species & & Observed frequencies & $\chi^{2}$ & & \\
\hline \multirow{3}{*}{ M. viciae } & whole insects & 0.50 & 6.80 & 0.034 & $*$ \\
\hline & crushed & 0.45 & 5.80 & 0.050 & $*$ \\
\hline & aphid + plant & 0.50 & 8.40 & 0.017 & $*$ \\
\hline \multirow{3}{*}{ A. pisum } & whole insects & 0.50 & 6.80 & 0.034 & $*$ \\
\hline & crushed & 0.65 & 16.40 & $<0.001$ & $* * *$ \\
\hline & aphid + plant & 0.55 & 10.00 & 0.008 & $* *$ \\
\hline \multirow{3}{*}{ A. fabae } & whole insects & 0.55 & 10.00 & 0.008 & $* *$ \\
\hline & crushed & 0.55 & 9.60 & 0.010 & $* *$ \\
\hline & aphid + plant & 0.75 & 26.80 & $<0.001$ & $* * *$ \\
\hline- & (E)- $\beta$-farnesene & 0.65 & 16.40 & $<0.001$ & $* * *$ \\
\hline- & Plant alone & 0.15 & 3.20 & 0.144 & NS \\
\hline
\end{tabular}

Observed frequencies relate to the final choice of E. balteatus larvae: the odour sources were compared to the corresponding expected frequency ( 1 odour-source arm and 3 control arms) using a $\chi^{2}$ test. ${ }^{*}, * *, * * *$ indicate significant differences at $\mathrm{P}<0.05, \mathrm{P}$ $<0.01$ and $\mathrm{P}<0.001$ respectively, and NS for not significantly different. 

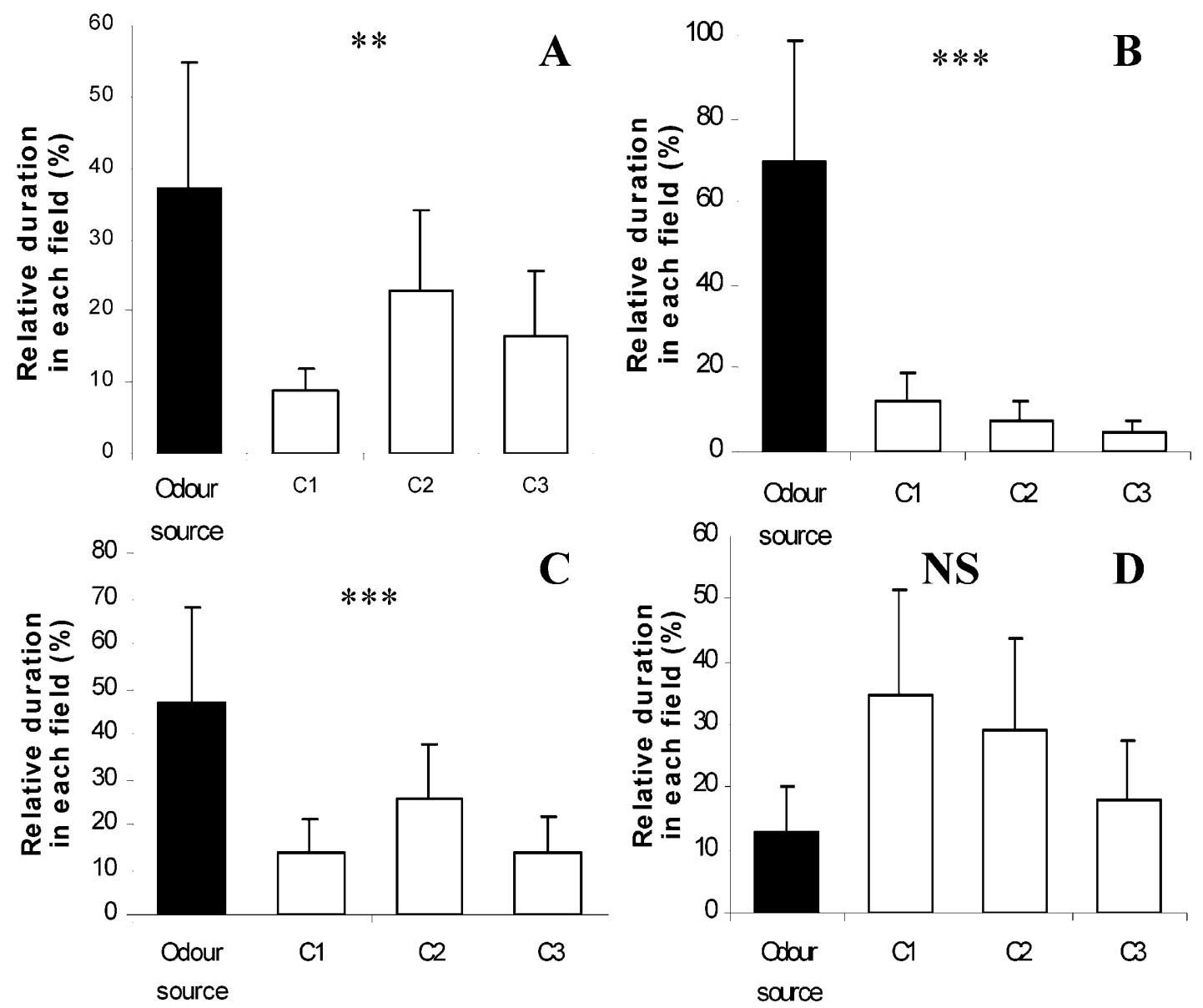

Fig. 3. Mean relative time (\%) spent in each field of a four-arm olfactometer by Episyrphus balteatus larvae exposed to associations of Vicia faba plants with whole Megoura viciae (A), Acyrthosiphon pisum (B) and Aphis fabae (C). Vicia faba plants alone were also used as an odour source (D). Error bars represent standard deviation of the mean. NS, ** and *** indicate no significance, significant differences at $\mathrm{P}<0.01$ and $\mathrm{P}<0.001$ respectively.

farnesene in hexane solution was highly significantly attractive to the hoverfly larvae.

The prey localisation by the hoverfly larvae using crushed or unstressed whole aphids from three species reared on $V$. faba are presented in Table 1 . Each of the three aphid species significantly attracted the predatory syrphid larvae when presented either as whole insects or crushed and the pure (E)- $\beta$-farnesene solution was also highly attractive. All of the three associations of $V$. faba leaves and A. pisum, M. viciae or A. fabae were similarly attractive for the E. balteatus larvae. Only the plant sample without aphids did not significantly attract the predatory larvae.
GC-MS analysis of volatiles from aphids and the host plant are presented in Table 2. Crushed A. pisum and A. fabae released only (E)- $\beta$-farnesene while $M$. viciae mainly emitted other terpenes, namely $\alpha$ - and $\beta$-pinene and limonene. The pure (E)- $\beta$-farnesene in hexane solution was found to include only a single molecule. No volatiles were detected from bean leaves using our SPME technique.

\section{DISCUSSIONS}

Aphid samples from all three tested species were found to be effective kairomone cues for E. balteatus; attraction therefore was not dependent on the terpene hydrocarbon

TABLE 2. GC-MS identification and relative proportion (in \%) of volatile molecules released from aphid and plant samples. (E)- $\beta$ farnesene $(\mathrm{EBF})$ pure solution was also analysed.

\begin{tabular}{|c|c|c|c|c|c|}
\hline \multicolumn{2}{|c|}{ Identified molecules } & \multirow{2}{*}{$\begin{array}{c}\alpha \text {-pinene Rt } 8.9 \\
-\end{array}$} & \multirow{2}{*}{$\frac{\beta \text {-pinene Rt 9.6 }}{-}$} & \multirow{2}{*}{$\begin{array}{c}\text { Limonene Rt } 9.9 \\
-\end{array}$} & \multirow{2}{*}{$\frac{(E)-\beta \text {-farnesene Rt } 17.6}{100.0}$} \\
\hline & A. pisum & & & & \\
\hline \multirow[t]{2}{*}{ Aphid species } & A. fabae & - & - & - & 100.0 \\
\hline & M. viciae & 11.8 & 68.0 & 6.2 & 14.0 \\
\hline Host plant & V. $f a b a$ & - & - & - & - \\
\hline \multicolumn{2}{|c|}{ Purified EBF } & - & - & - & 100.0 \\
\hline
\end{tabular}

Values indicating retention times (Rt) are also presented. (-) corresponds to "no molecules detected". 
volatile pattern released by prey. Indeed, the same attractive behaviour of the hoverfly was observed for $A$. pisum and $A$. fabae, both (E)- $\beta$-farnesene producers, and $M$. viciae (which releases a mixture of three terpenic hydrocarbons). Our results demonstrate that there was a systematic response of this polyphagous aphid predator towards volatiles released from several potential prey.

Both crushed and whole unstressed aphids were attractive for the predatory syrphid larvae, unlike many other predator species. Several beneficials do not positively respond to the emitted chemical cues when whole aphids are used alone as odour sources. The parasitoid Aphidius ervi Haliday (Braconidae) was not attracted by whole $A$. pisum aphids (Du et al., 1996); A. bipunctata significantly respond to only crushed A. pisum and Myzus persicae, whatever host-plant species they were fed on (Francis et al., 2004a). It was advanced that crushed aphids thus released higher and sufficient levels of volatile substances to be perceived by the predators. That means that the chemical cues released by whole aphids were not sufficient to allow the prey localisation by the aphidophagous beneficials. To be an effective kairomone source, the whole aphid colony must be more important than the one used as samples in the olfactometry assays. Using another prey species, Han \& Chen (2002) showed that the tea aphids send out odours attracting C. septempunctata when the number of aphids was at least 2000. The latter authors found that $C$. septempunctata was the most sensitive species between three tested natural enemies. Here, $E$. balteatus was found to be very sensitive to small amounts of volatiles from aphids, since the syrphid larvae responded positively to almost 500 whole aphids (corresponding to $250 \mathrm{mg}$ samples) as odour sources.

Until our results, when the aphid species used as odour sources release molecules other than (E)- $\beta$-farnesene, an absence of any infochemical effect has been observed for aphidophagous insects. Indeed, other components from aphids modulated the kairomonal effect toward the predatory species. For example, Al Abassi et al. (2000) demonstrated that the attractivity of (E)- $\beta$-farnesene for $C$. septempunctata decreased with increasing amounts of $\beta$-caryophyllene. Isothiocyanate emissions (detected by GC-MS) from Brevicoryne brassicae was considered to be acting as a kairomone inhibitor, informing $A$. bipunctata, the two spot ladybird, of prey unsuitability (Francis et al., 2004a).

In the current study, the release of several terpenes from $M$. viciae was not less attractive for $E$. balteatus larvae than the two other aphid species, which emitted only (E)- $\beta$-farnesene. E. balteatus is well known to be adapted to a broad range of aphid preys in terms of development and reproductive efficacy (Gilbert, 1986; Vanhaelen et al., 2002), and this species has been demonstrated here to be less restrictive in its prey location behaviour. We think therefore that E. balteatus could be considered as more of a generalist, showing a higher potential as an aphid biological control agent than other aphidophagous predators such as ladybirds.
The tested plant-aphid associations were all attractive to E. balteatus. These results are in partial accordance with previous works on beneficials. A too low concentration of volatiles liberated by the aphid and host plant samples has often been considered to explain a lack of attraction for predators such as ladybirds or parasitoids. The foraging behaviour of the aphid parasitoid Aphidius ervi was shown to be influenced by semiochemicals emitted by aphid-infested plants only when a certain threshold of infestation has been reached in terms of number of aphids and hours of feeding activity (Guerrieri et al., 1999). A volatile dose-dependent response of another predatory beetle, C. septempunctata towards prey-host plant complex has also been observed: significant differences towards odour source and control in a Y olfactometer were only observed when the seven-spot ladybird was exposed to at least 30 aphid damaged shoots with 1200 tea aphids. Below this amount of volatile emitted from biological sample, no significant attraction on the predator was observed (Han \& Chen, 2002). In the current work, the presence of whole aphids of whatever species, with the plant samples was sufficient to ensure hoverfly orientation. E. balteatus was able to locate every tested potential prey when associated with the host plant.

In conclusion, we have shown that, contrary to other aphidophagous predators and parasitoids, E. balteatus not only reacts to (E)- $\beta$-farnesene, but responds also to other semiochemical cues from prey. Host-plant and aphidhost-plant complexes represent effective infochemical sources for syrphid larvae under our experimental observations. More than other aphidophagous beneficial species, the systematic response of a polyphagous aphid predator to several potential preys confirms the potential of $E$. balteatus in aphid biological control.

ACKNOWLEDGEMENT. Our work has been funded by FNRS (Fonds national de la Recherche scientifique) grant (M 2.4.586.04.F).

\section{REFERENCES}

Al Abassi S., Birkett M.A., Pettersson J., Pickett J.A., WadHAMs L.J. \& Woodcock C.M. 2000: Response of the sevenspot ladybird to an aphid alarm pheromone and alarm pheromone inhibitor is mediated by paired olfactory cells. $J$. Chem. Ecol. 26: 1765-1771.

Bargen H., Saudhof K. \& Poehling H.-M. 1998: Prey finding by larvae and adult females of Episyrphus balteatus. Entomol. Exp. Appl. 87: 245-254.

Chambers R.J., Sunderland K.D., Stacey D.L. \& Wyatt I.J. 1986: Control of cereal aphids in winter wheat by natural enemies: aphid-specific predators, parasitoids and pathogenic fungi. Ann. Appl. Biol. 108: 219-231.

Dagnelie P. 1973: Théories et Méthodes Statistiques. Vol. 2. Presses agronomiques, Gembloux, Belgium, $227 \mathrm{pp}$.

Du Y.-J., Poppy G.M. \& Powell W. 1996: Relative importance of semiochemicals from first and second trophic levels in host foraging behavior of Aphidius ervi. J. Chem. Ecol. 22: 1591-1605.

Francis F., Lognay G., Gaspar C. \& Haubruge E. 2004a: Olfactory responses to aphid and host plant volatile releases: (E)- $\beta$-farnesene an effective allomone for the predator Adalia bipunctata. J. Chem. Ecol. 30: 741-755. 
Francis F., Haubruge E. \& Lognay G. 2004b: Terpene releases from twenty three aphid species and implication of related host plant. J. Appl. Entomol. 129: 6-11.

Gilbert F.S. 1986: Hoverflies. Naturalist Handbook 5. Cambridge University Press, London, 66 pp.

Guerrieri E., Poppy G.M., Powell W., Tremblay E. \& PennacCHIO F. 1999: Induction and systemic release of herbivore induced plant volatiles mediating in flight orientation of Aphidius ervi (Hymenoptera: Braconidae). J. Chem. Ecol. 25: 1247-1261

HAN B. \& Chen Z. 2002: Behavioral and electrophysiological responses of natural enemies to synomones from tea shoots and kairomones from tea aphids, Toxoptera aurantii. J. Chem. Ecol. 28: 2203-2220.

PopPY G.M. 1997: Tritrophic interactions: improving ecological understanding and biological control. Endeavour 21: 61-65.

Tenhumberg B. \& Poehling H.-M. 1995: Syrphids as natural enemies of cereal aphids in Germany: Aspects of their biology and efficacy in different years and regions. Agric. Ecosyst. Environ. 52: 39-43.
Vanhaelen N., Gaspar C. \& Francis F. 2002: Influence of prey host plant on development and reproduction of two aphidophagous predators, Episyrphus balteatus (Diptera: Syrphidae) and Adalia bipunctata (Coleoptera: Coccinellidae). Eur. J. Entomol. 99: 561-564.

Vet L.E.M. \& Dicke M. 1992: Ecology of infochemical use by natural enemies in a tritrophic context. Annu. Rev. Entomol. 37: 141-172.

Vet L.E.M., van Lenteren J.C., Heymans M. \& Meelis E. 1983: An airflow olfactometer for measuring olfactory responses of hymenopterous parasitoids and other small insects. Physiol. Entomol. 8: 97-106.

Zhu J., Cossé A.A., Obrycki J.J., Boo K.S. \& BaKer T.C. 1999: Olfactory reactions of the twelve-spotted lady beetle, Coleomegilla maculata and the green lacewing, Chrysoperla carnea to semiochemicals released from their prey and host plant: electroantennogram and behavioral responses. J. Chem. Ecol. 25: $1163-1177$.

Received September 29, 2004; revised and accepted April 22, 2005 